\title{
LA-UR-13-21171
}

Approved for public release; distribution is unlimited.

Title:

Density Functional Study of the Structure, Stability and Oxygen Reduction Activity of Ultrathin Platinum Nanowires

$\begin{array}{ll}\text { Author(s): } & \text { Gonzales, Ivana } \\ & \text { Henson, Neil J. } \\ & \text { Garzon, Fernando H. }\end{array}$

Intended for:

Review of the Program at University of New Mexico, Albuquerque

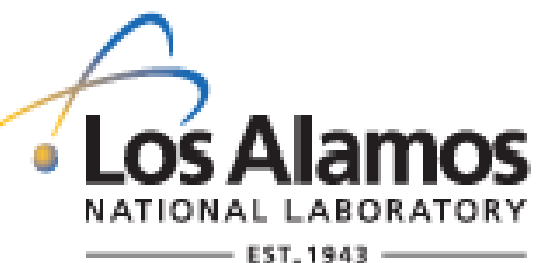

Disclaimer:

Los Alamos National Laboratory, an affirmative action/equal opportunity employer,is operated by the Los Alamos National

Security, LLC for the National NuclearSecurity Administration of the U.S. Department of Energy under contract DE-AC52-06NA25396. By approving this article, the publisher recognizes that the U.S. Government retains nonexclusive, royalty-free license to publish or reproduce the published form of this contribution, or to allow others to do so, for U.S. Government purposes.

Los Alamos National Laboratory requests that the publisher identify this article as work performed under the auspices of the

U.S. Departmentof Energy. Los Alamos National Laboratory strongly supports academic freedom and a researcher's right to publish; as an institution, however, the Laboratory does not endorse the viewpoint of a publication or guarantee its technical correctness. 


\section{Density Functional Study of the Structure, Stability and Oxygen Reduction Activity of Ultrathin Platinum Nanowires}

Ivana Gonzales, Fernando Garzon, Neil Henson

Physics and Chemistry of Materials

Los Alamos National Laboratory, Los Alamos, USA

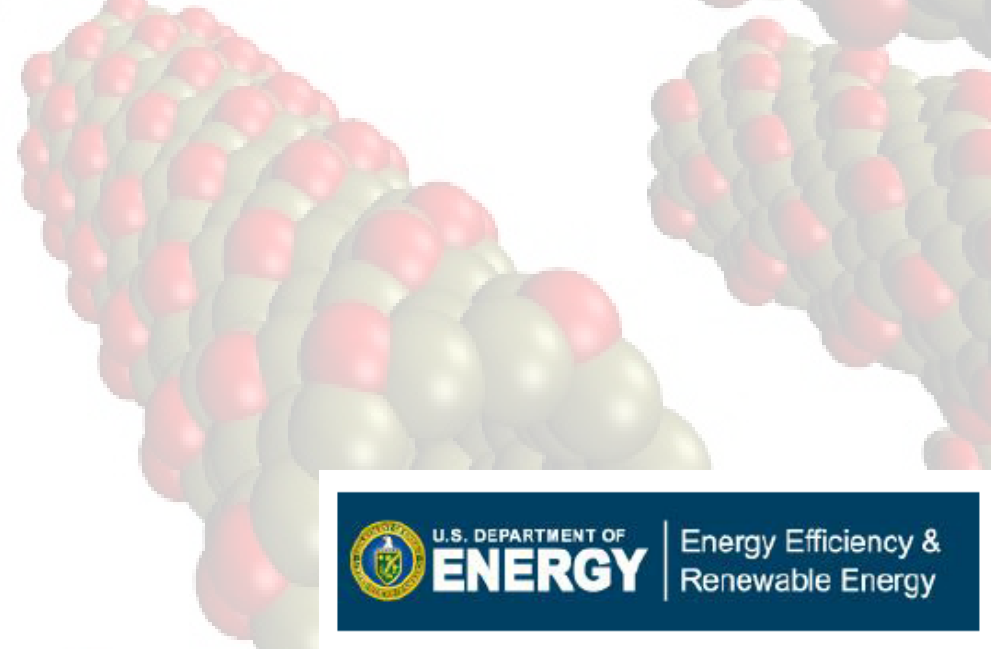




\section{metal nanotubes}

- magic "structure" and conductance - nanoelectronics

- Au, Ag, Pt nanotubes less then $2 \mathrm{~nm}$ thickness have been synthesized by an electron-beam technique in an UHV-TEM
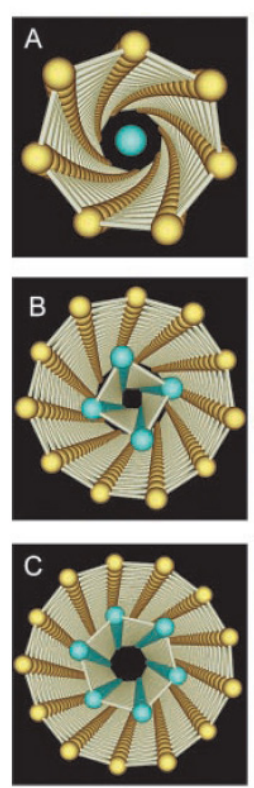
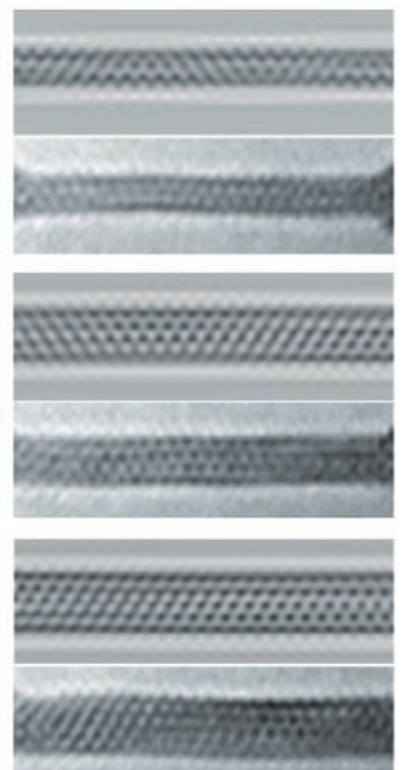
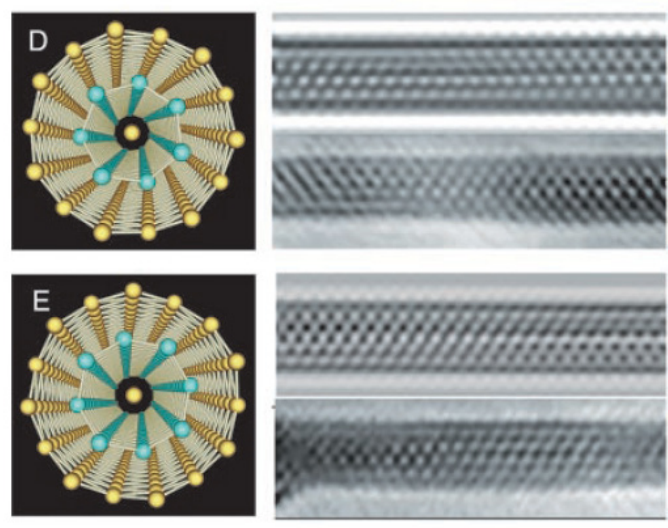

$1 \mathrm{~nm}$

Kondo et al. Science, 289, 606

\section{- Los Alamos}




\section{metal nanotubes}

- Pt nanotubes - 1.0 and $0.5 \mathrm{~nm}$ in diameter

$0.5 \mathrm{~nm}-$ six atomic rows coiling around tubes axes

$1 \mathrm{~nm}$ - 13-6 multishell structure

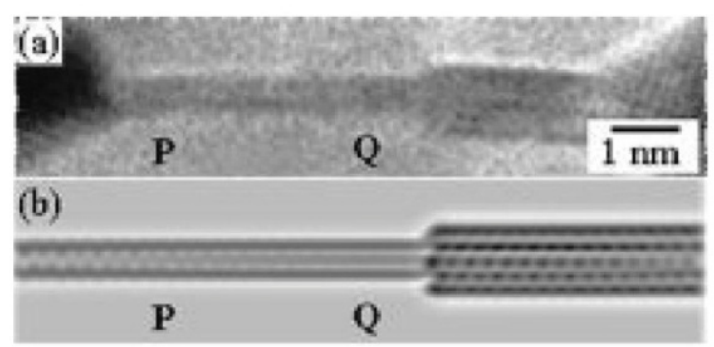

(c)

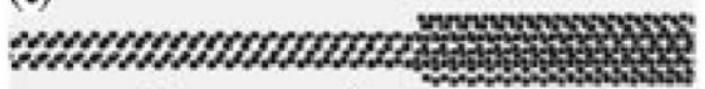

$\mathbf{P}$

Q

(d)

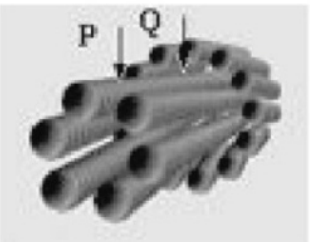

Figure: HR-TEM image of platinum nanotube

Y. Oshima et. al, Phys. Rev. B, 65, 121401 (2002) 


\section{metal nanotubes}

\section{Pt nanotubes - electrocatalysis}

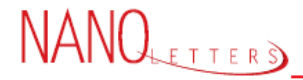

\section{Size-Dependent Enhancement of} Electrocatalytic Performance in Relatively Defect-Free, Processed Ultrathin Platinum Nanowires

Christopher Koenigsmann, ${ }^{\dagger}$ Wei-ping Zhou, ${ }^{\dagger}$ Radoslav R. Adzic, ${ }^{\dagger}{ }^{\dagger}$ Eli Sutter,${ }^{\S}$ and Stanislaus S. Wong

\footnotetext{
ABSTRACT We report on the synthesis, characterization, and electrocatalytic performance of ultrathin Pt nanowires with a diameter $1.3 \pm 0.4 \mathrm{~nm}$. The ectrotaly activity of these nanowios to activity of both supported and unsupported Pt nanoparticles as well as with previously synthesized Pt nanotubes. Our ultrathin acidtreated, unsupported nanowires displayed an electrochemical surface area activity of $1.45 \mathrm{~mA} / \mathrm{cm}^{2}$, which was nearly 4 times greater than that of analogous, unsupported platinum nanotubes and 7 times greater than that of commercial supported platinum nanoparticles.

KEYWORDS Platinum, nanowires, electrocatalysis, oxygen reduction reaction
}

pubs.acs.org/NanoLett

un with a diameter
with a diameter of
in relation to the
rly 4 timesthes greater
num nanoparticles.

\section{NATIONAL LABORATORY}

Oxygen-Reduction Catalysts

DOI: 10.1002/anie.200700894

Supportless Pt and PtPd Nanotubes as Electrocatalysts for Oxygen-Reduction Reactions***

Zhongwei Chen, Mahesh Waje, Wenzhen Li, and Yushan Yan*

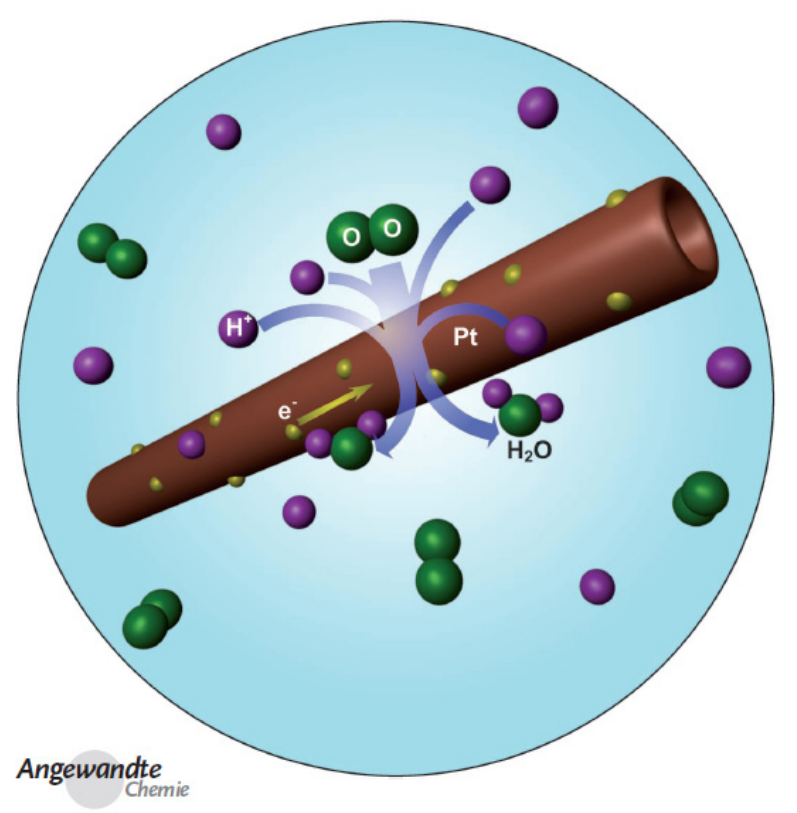




\section{Pt nanotubes}

\section{PtNT: Rolling-up Pt(111) sheet to form a tube}
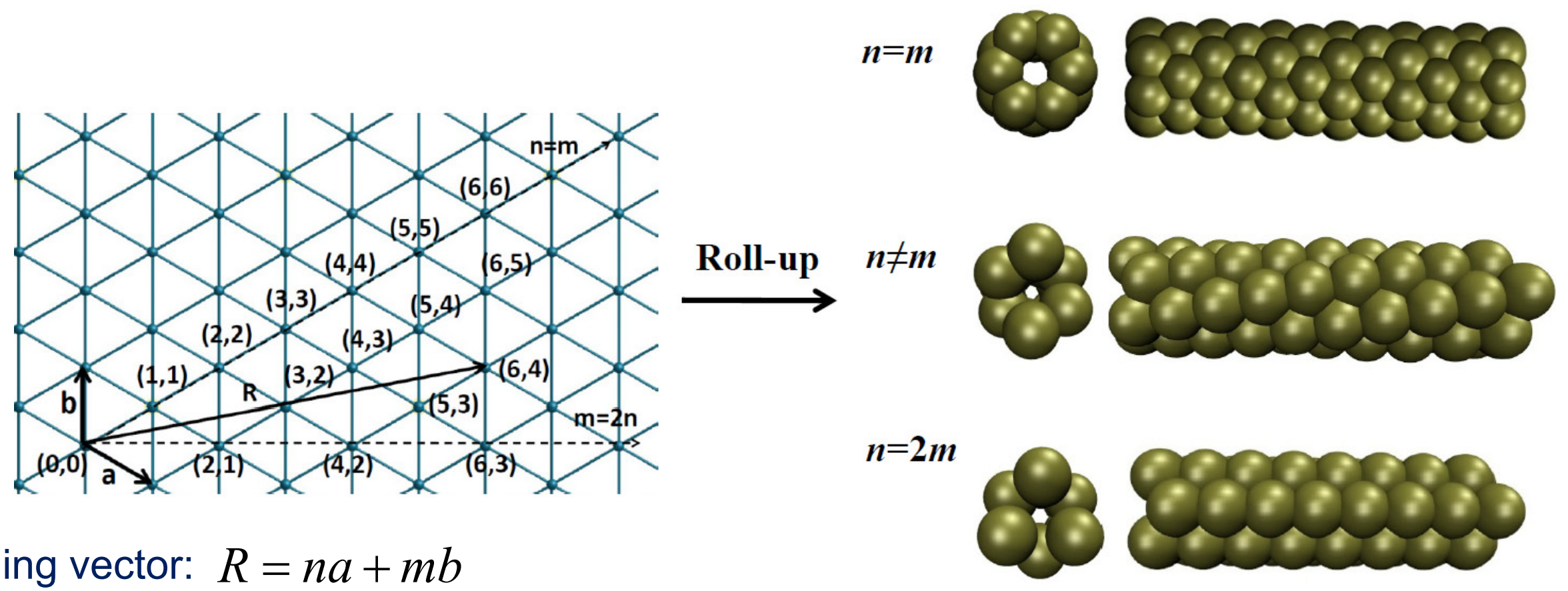

rolling vector: $R=n a+m b$

$$
\begin{gathered}
r=\frac{\sqrt{2} a_{c}}{4 \pi} \sqrt{n^{2}+m^{2}-n m} \\
a_{c}=3.70-3.85 \AA
\end{gathered}
$$




\section{Methodology}

Reactions connecting different states of the metal surface $\left({ }^{*}\right)$ in the ORR mechanism

$$
\left.\begin{array}{c}
\frac{1}{2} \mathrm{O}_{2}+{ }^{*} \\
\mathrm{O}^{*}+\mathrm{e}^{-}+\mathrm{H}^{+} \\
\mathrm{OH}^{*}+\mathrm{e}^{-}+\mathrm{H}^{+} \rightarrow \mathrm{OH}^{*}+\mathrm{H}_{2} \mathrm{O}(\mathrm{l})
\end{array}\right] \begin{aligned}
& \text { relative to the standard } \\
& \text { hydrogen electrode } \\
& \mathrm{e}^{-}+\mathrm{H}^{+}(\mathrm{aq})=1 / 2 \mathrm{H}_{2}(\mathrm{~g})
\end{aligned}
$$

Free gibbs energy of the reactions

$$
\begin{gathered}
\Delta G_{\mathrm{w}, \mathrm{water}}=\Delta E_{\mathrm{w}, \text { water }}+\Delta \mathrm{ZPE}+T \Delta S \\
\Delta G(U, p \mathrm{H}, T=298 K)=\Delta G_{\mathrm{w}, \text { water }} \underbrace{e U}_{\text {bias effect }}+\underbrace{k T \ln (10) p \mathrm{H}}_{\begin{array}{c}
\text { correction for the free } \\
\text { energy of } \mathrm{H}+
\end{array}}
\end{gathered}
$$




\section{Technical details}

- VASP program

- DFT with PAW method using GGA approximation with PW91 exchange-correlation term

- $23 \AA \times 23 \AA \times n L$ cell, vacuum space twice the tubes diameter

- $(1 \times 1 \times 4)-(1 \times 1 \times 21)$ k-point Monkhorst-Pack mesh

- plane-wave basis with a cutoff energy of $400 \mathrm{eV}$

- Methfessel-Paxton smearing of order 2 with sigma value of $0.2 \mathrm{eV}$

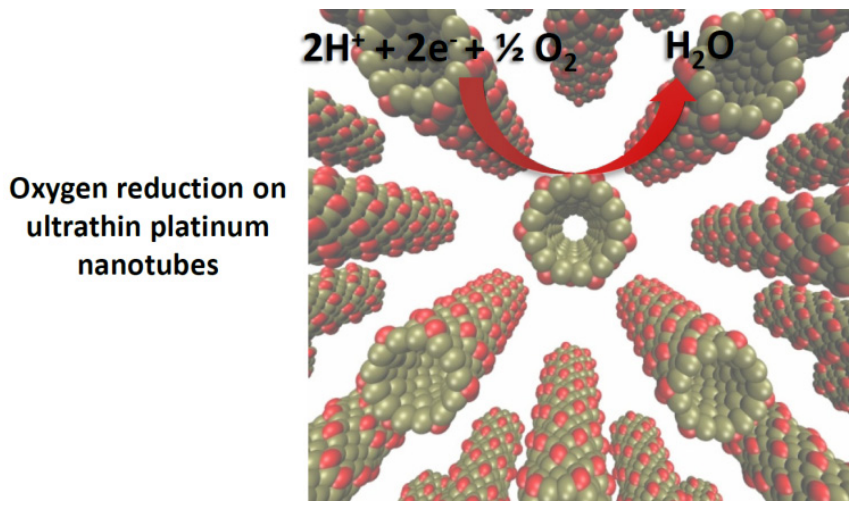




\section{Pt nanotubes}
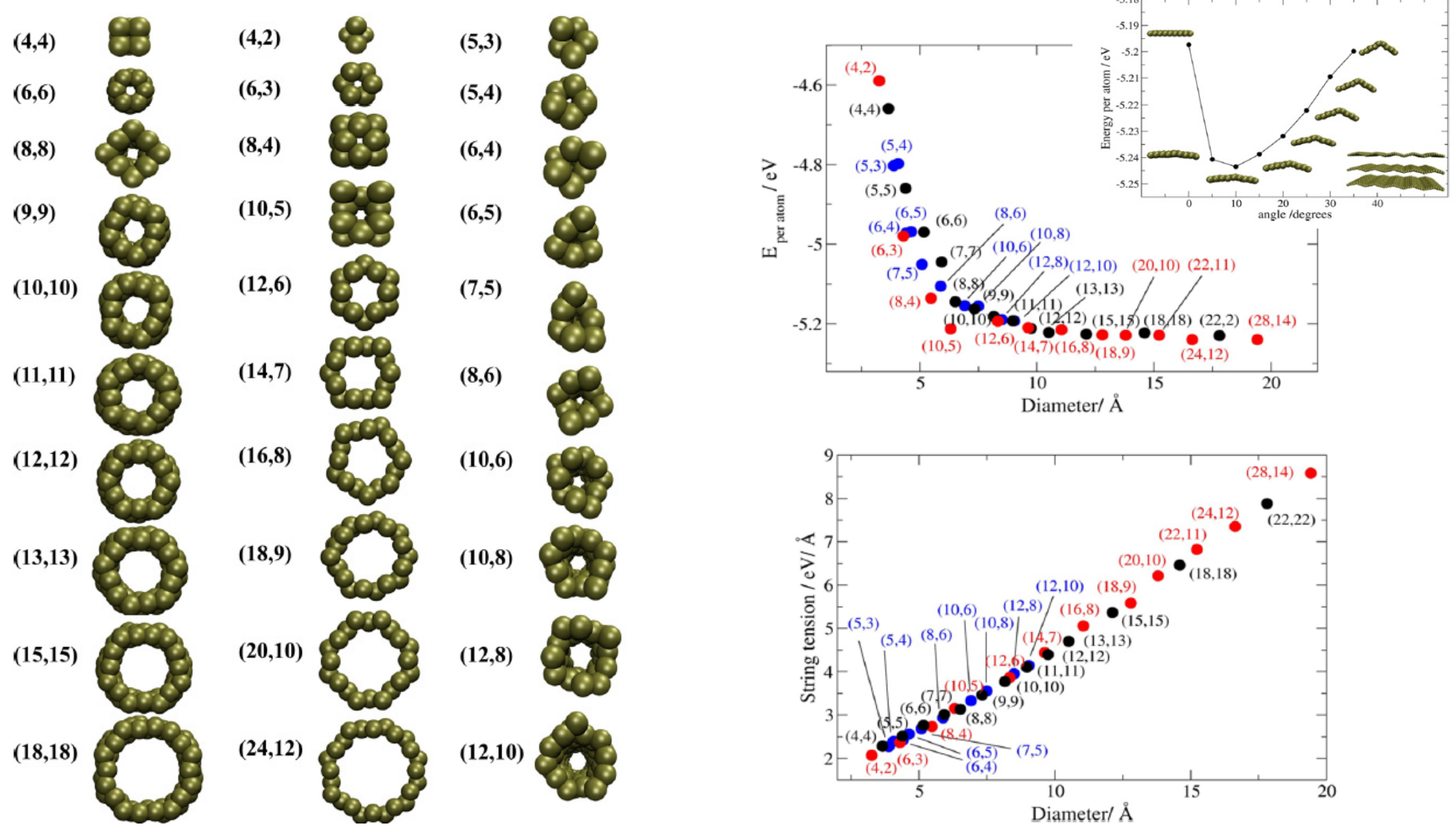


\section{Pt nanowires}

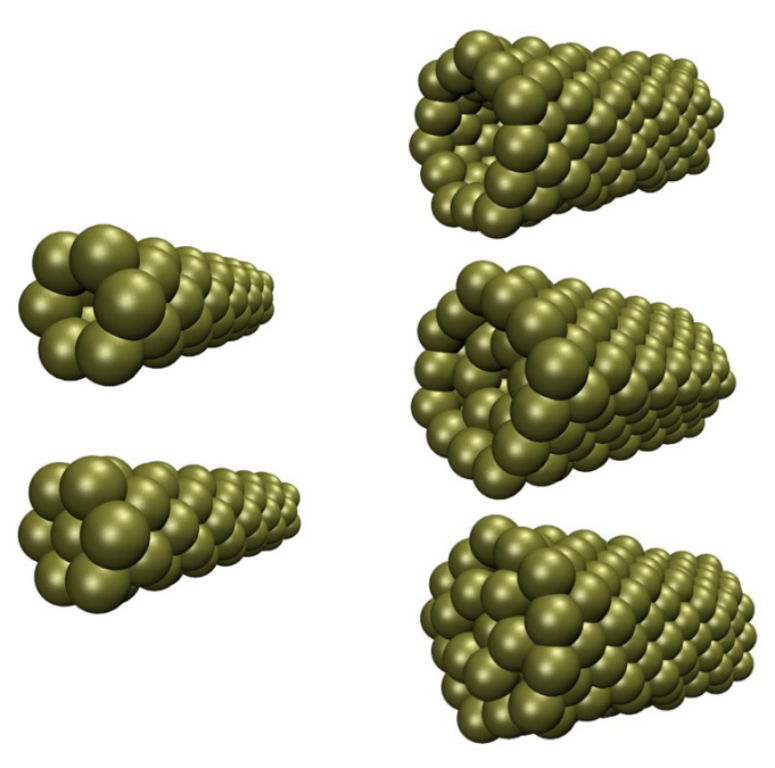

$(6,6)$ NT

$(13,13)$ NT

$(6,6) \mathrm{NW}$

$(6,6) @(13,13)$ NT

$(6,6) @(13,13)$ NW 


\section{Pt nanotubes \& nanowires: density of states}
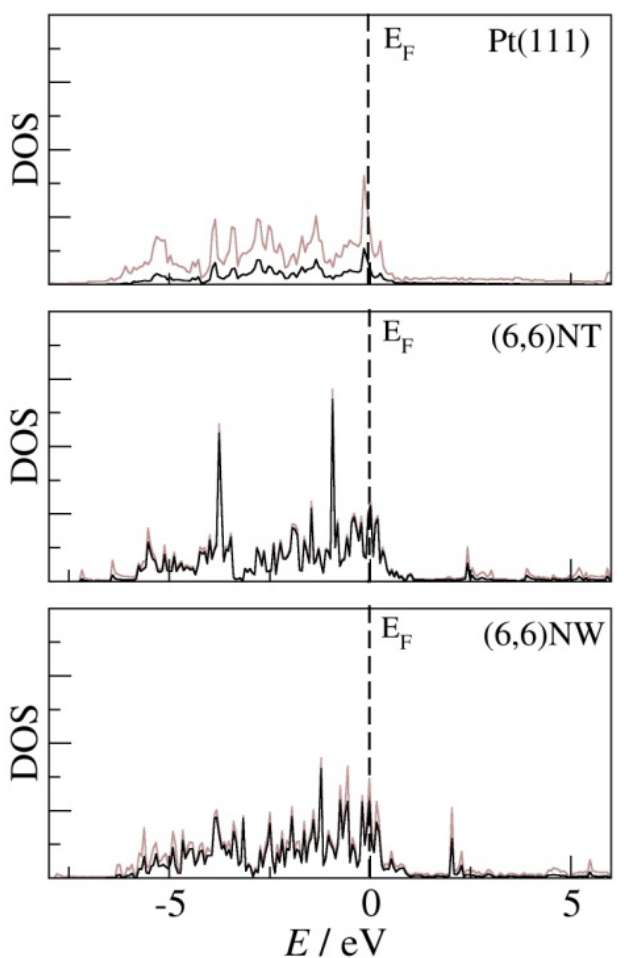

$E / \mathrm{eV}$
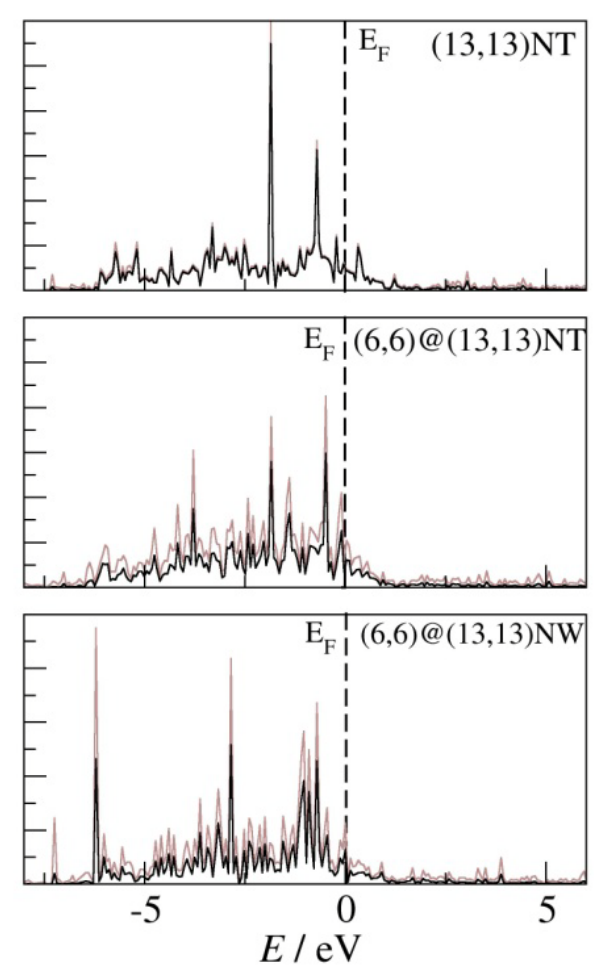

- electronic states distributed continuously from $-7 \mathrm{eV}$ all the way up, much smaller above $1 \mathrm{eV}$

- compared to DOS of Pt, many conspicuous peaks

- enables us to calculate the position of the $d$-band center $-d$-band theory 


\section{Pt nanotubes \& nanowires: band structure}
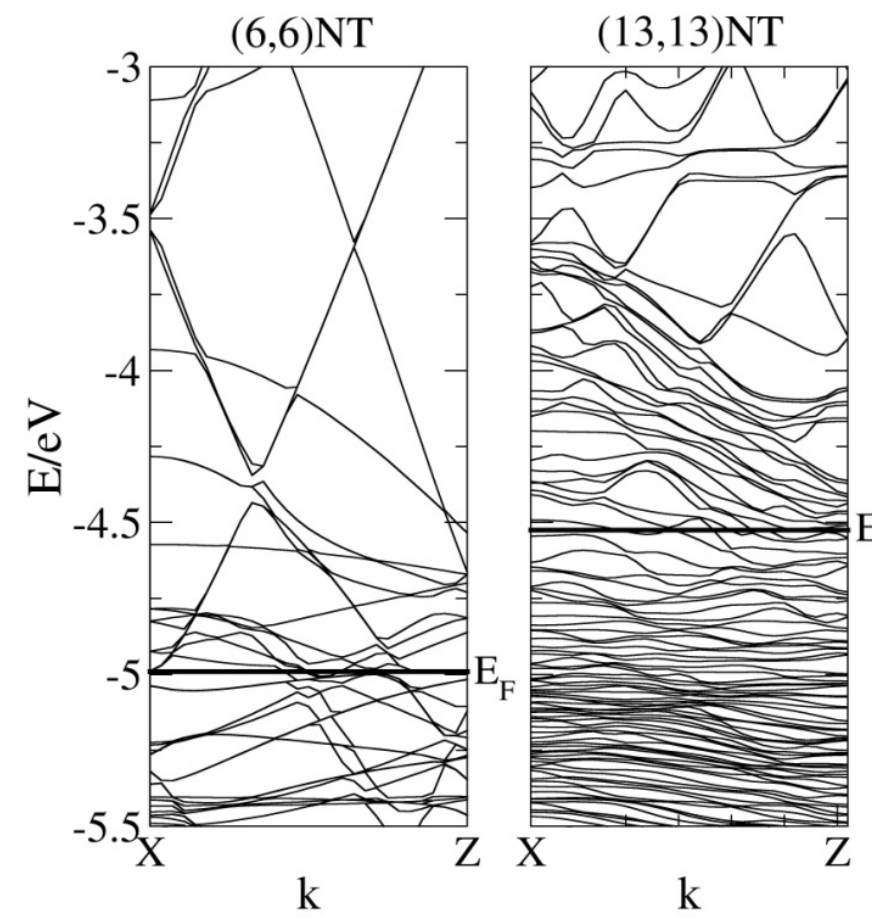

$\mathrm{k}$

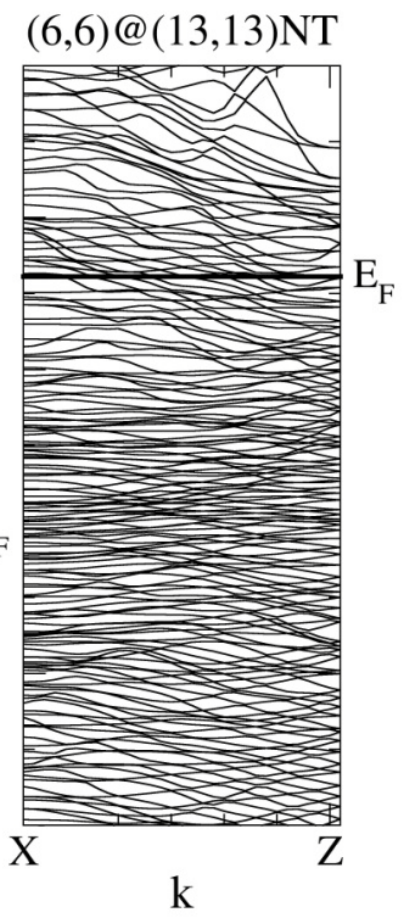

- number of electronic bands that cross Fermi level (conduction channels) quantized - conductance quantized

- position of Fermi level pushed up, number of conduction channels increases as the number of rows in NT increase 


\section{Pt nanotubes \& nanowires: ORR}

\begin{tabular}{|c|c|c|c|c|c|c|c|c|c|}
\hline & \multirow[b]{2}{*}{ system } & \multicolumn{3}{|c|}{ oxygen (fcc site) } & \multicolumn{3}{|c|}{ hydroxyl (atop site) } & \multicolumn{2}{|c|}{ hydroperoxyl (T-T* and atop) } \\
\hline & & $\begin{array}{c}0.25 \mathrm{ML} \\
E_{\text {ad }} / \mathrm{eV} \\
\end{array}$ & $\begin{array}{c}0.33 \mathrm{ML} \\
E_{\text {ad }} / \mathrm{eV} \\
\end{array}$ & $\begin{array}{l}0.5 \mathrm{ML} \\
E_{\mathrm{ad}} / \mathrm{eV} \\
\end{array}$ & $\begin{array}{c}0.25 \mathrm{ML} \\
E_{\mathrm{ad}} / \mathrm{eV} \\
\end{array}$ & $\begin{array}{c}0.33 \mathrm{ML} \\
E_{\mathrm{ad}} / \mathrm{eV} \\
\end{array}$ & $\begin{array}{c}0.5 \mathrm{ML} \\
E_{\mathrm{ad}} / \mathrm{eV} \\
\end{array}$ & $\begin{array}{c}0.25 \mathrm{ML} \\
E_{\mathrm{ad}} / \mathrm{eV} \\
\end{array}$ & $\begin{array}{c}0.33 \mathrm{ML} \\
E_{\mathrm{ad}} / \mathrm{eV} \\
\end{array}$ \\
\hline & $\mathbf{P t}$ & -4.42 & -4.25 & -4.07 & -2.88 & -2.92 & -3.09 & $-1.24 * /-1.15$ & $-1.27 * /-1.20$ \\
\hline \multirow[t]{2}{*}{$\sim 0.5 \mathrm{~nm}$} & $(6,6) \mathrm{NT}$ & -4.72 & -4.41 & -4.46 & -3.54 & -3.53 & -3.52 & -1.83 & -1.78 \\
\hline & $(6,6) \mathrm{NW}$ & -4.62 & -4.38 & -4.33 & -3.30 & -3.42 & -3.36 & -1.75 & -1.69 \\
\hline \multirow{3}{*}{$\sim 1.0 \mathrm{~nm}$} & $(13,13) \mathrm{NT}$ & -4.14 & -3.90 & -3.92 & -2.83 & -2.87 & -2.85 & $-1.28 * /-1.42$ & -1.47 \\
\hline & $(6,6) @(13,13) \mathrm{NT}$ & -4.05 & -4.21 & -4.06 & -3.07 & -3.13 & -3.20 & $-1.24 * /-1.38$ & -1.41 \\
\hline & $(6,6) @(13,13) N W$ & -4.04 & -4.02 & -3.97 & -3.04 & -3.10 & -3.09 & -1.30 & -1.36 \\
\hline
\end{tabular}

- hydroperoxyl dissociates on most of the adsorption sites - 4e- ORR without peroxide formation preferred mechanism 


\section{Pt nanotubes \& nanowires: $d$-band theory}

\begin{tabular}{|c|c|c|c|c|c|}
\hline & \multirow[b]{2}{*}{ system } & \multicolumn{3}{|c|}{ oxygen (fcc site) } & \multirow[t]{2}{*}{ d-band center } \\
\hline & & $\begin{array}{c}0.25 \mathrm{ML} \\
E_{\mathrm{ad}} / \mathrm{eV} \\
\end{array}$ & $\begin{array}{c}0.33 \mathrm{ML} \\
E_{\mathrm{ad}} / \mathrm{eV} \\
\end{array}$ & $\begin{array}{c}0.5 \mathrm{ML} \\
E_{\mathrm{ad}} / \mathrm{eV} \\
\end{array}$ & \\
\hline & $\mathbf{P t}$ & -4.42 & -4.25 & -4.07 & $-1.78 \mathrm{eV}$ \\
\hline \multirow[t]{2}{*}{$\sim 0.5 \mathrm{~nm}$} & $(6,6) \mathrm{NT}$ & -4.72 & -4.41 & -4.46 & $-1.81 \mathrm{eV}$ \\
\hline & $(6,6) \mathrm{NW}$ & -4.62 & -4.38 & -4.33 & $-1.75 \mathrm{eV}$ \\
\hline \multirow{3}{*}{$\sim 1.0 \mathrm{~nm}$} & $(13,13) \mathrm{NT}$ & -4.14 & -3.90 & -3.92 & $-2.00 \mathrm{eV}$ \\
\hline & $(6,6) @(13,13) \mathrm{NT}$ & -4.05 & -4.21 & -4.06 & $-2.05 \mathrm{eV}$ \\
\hline & $(6,6) @(13,13) N W$ & -4.04 & -4.02 & -3.97 & $-2.13 \mathrm{eV}$ \\
\hline
\end{tabular}

* T-T site dissociates
- no correlation between the shift in the $d$-band center relative to Fermi level and the oxygen adsorption energy

- adsorption of chemical species changes the local environment of the adsorption site (!)

- inadequacy of simple descriptors to predict reactivity 


\section{Pt nanotubes phase diagram}

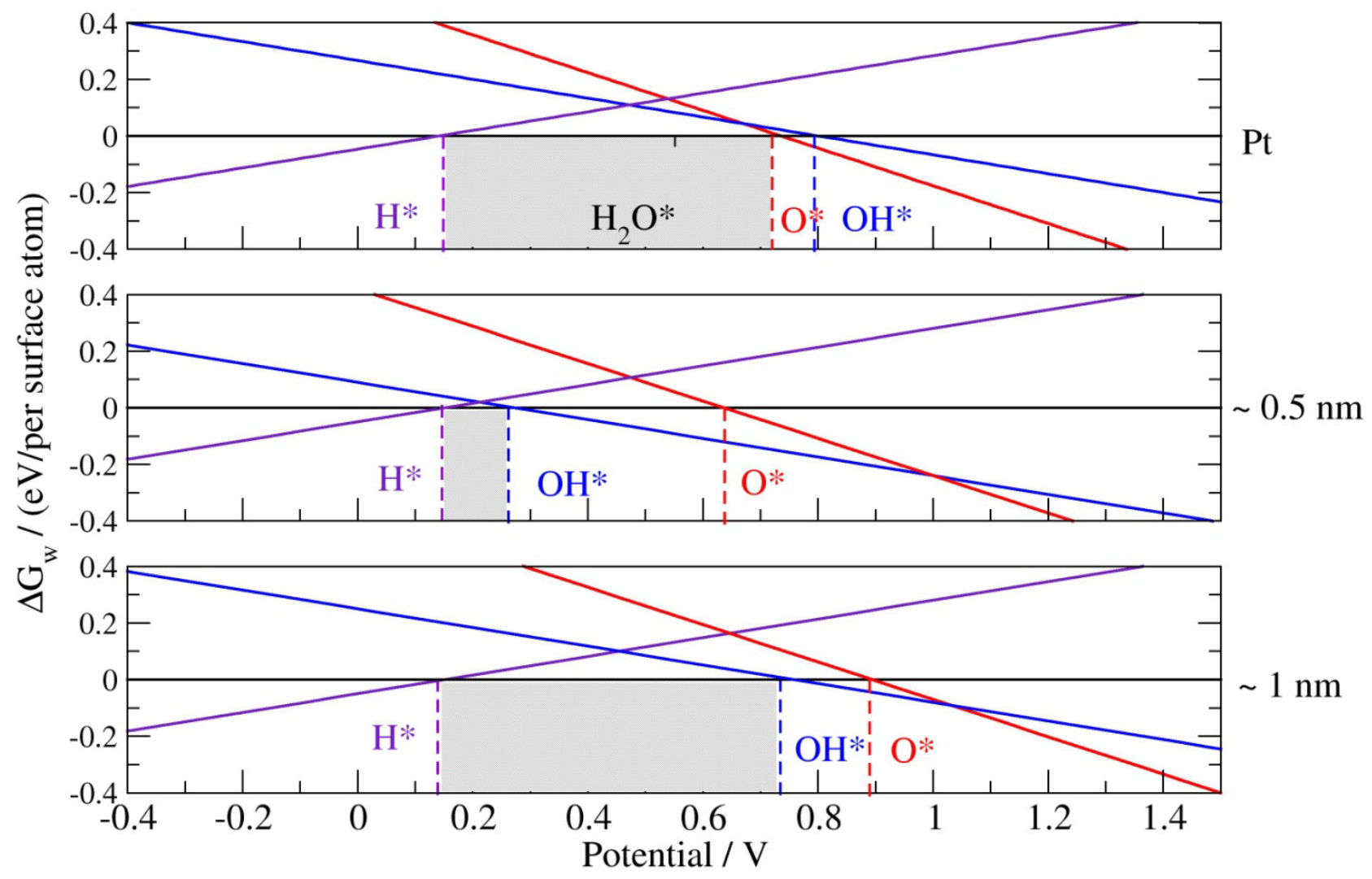




\section{Dissociative oxygen reduction reaction (ORR) mechanism}

$$
\begin{aligned}
\frac{1}{2} \mathrm{O}_{2}+* & \rightarrow \mathrm{O}^{*} \\
\mathrm{O}^{*}+\mathrm{e}^{-}+\mathrm{H}^{+} & \rightarrow \mathrm{OH}^{*} \\
\mathrm{OH}^{*}+\mathrm{e}^{-}+\mathrm{H}^{+} & \rightarrow *+\mathrm{H}_{2} \mathrm{O}(\mathrm{l})
\end{aligned}
$$

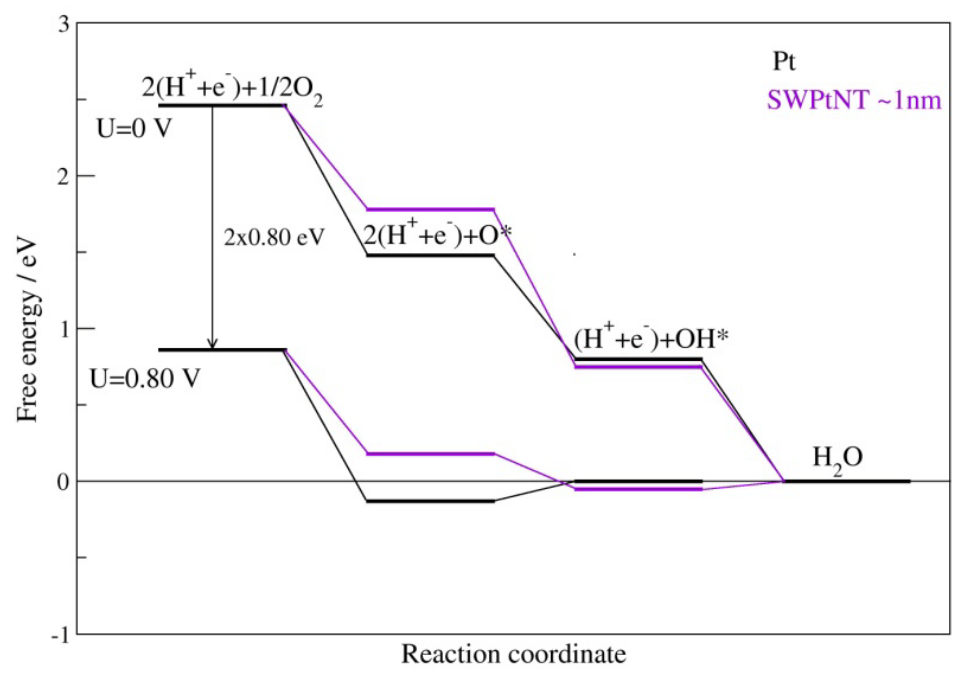

hollow single-wall nanotubes and non-hollow nanowires with diameters larger than $1 \mathrm{~nm}$ have smaller ORR overpotential than $\mathrm{Pt}(111)$ up to 100 $\mathrm{meV}$

in agreement with experimental

findings - Nano Lett. 2010, 19, 1806

Figure: Free-energy diagrams for ORR over Pt(111) surfaces and SWPtNT for cell potentials $U=0.80 \mathrm{~V}$ 


\section{Stability of the surfaces}

Electrochemical dissolution can severely decrease the performance of the material

Estimate of the shift in the electrochemical dissolution potential based on the change in cohesive energy relative to $\mathrm{Pt}(111)$

$$
\mathrm{M}_{N}(\text { surface }) \rightarrow \mathrm{M}_{N-1}+\mathrm{M}
$$




\section{Stability of the surfaces}

Table: surface cohesive energy of different tubes and the shift in the electrochemical dissolution potential relative to $\mathrm{Pt}(111)$

\begin{tabular}{|c|c|c|}
\hline system & $\Delta E / \mathrm{eV}$ & $\Delta U_{\text {corr }} / \mathbf{V}$ \\
\hline $\mathbf{P t}$ & 6.50 & 0.00 \\
\hline$(6,6) \mathrm{NT}$ & 5.27 & -0.62 \\
\hline$(6,6) N W$ & 5.54 & -0.49 \\
\hline$(13,13) \mathrm{NT}$ & 6.29 & -0.11 \\
\hline$(6,6) @(13,13) \mathrm{NT}$ & 5.50 & -0.50 \\
\hline$(6,6) @(13,13) \mathrm{NW}$ & 5.70 & -0.40 \\
\hline
\end{tabular}

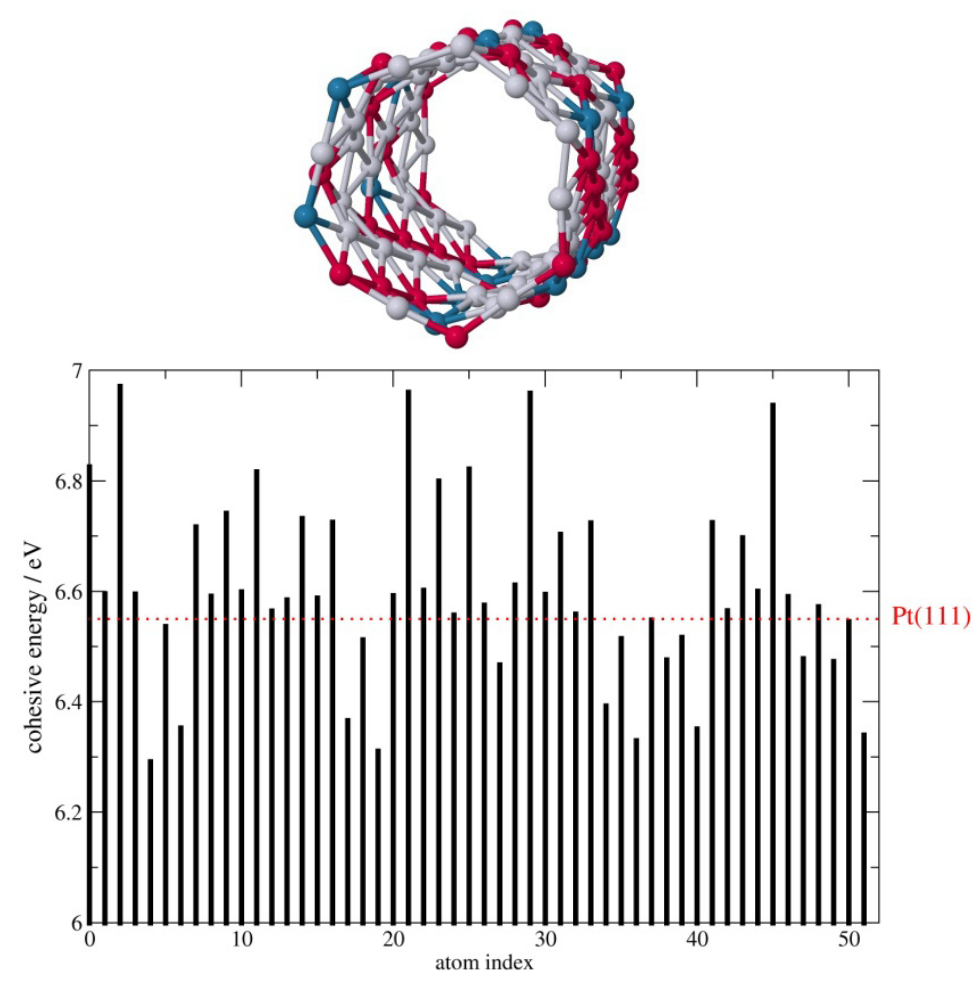

Figure. Surface cohesive energy of atoms in $(13,13)$ tube 


\section{Pourbaix diagrams}

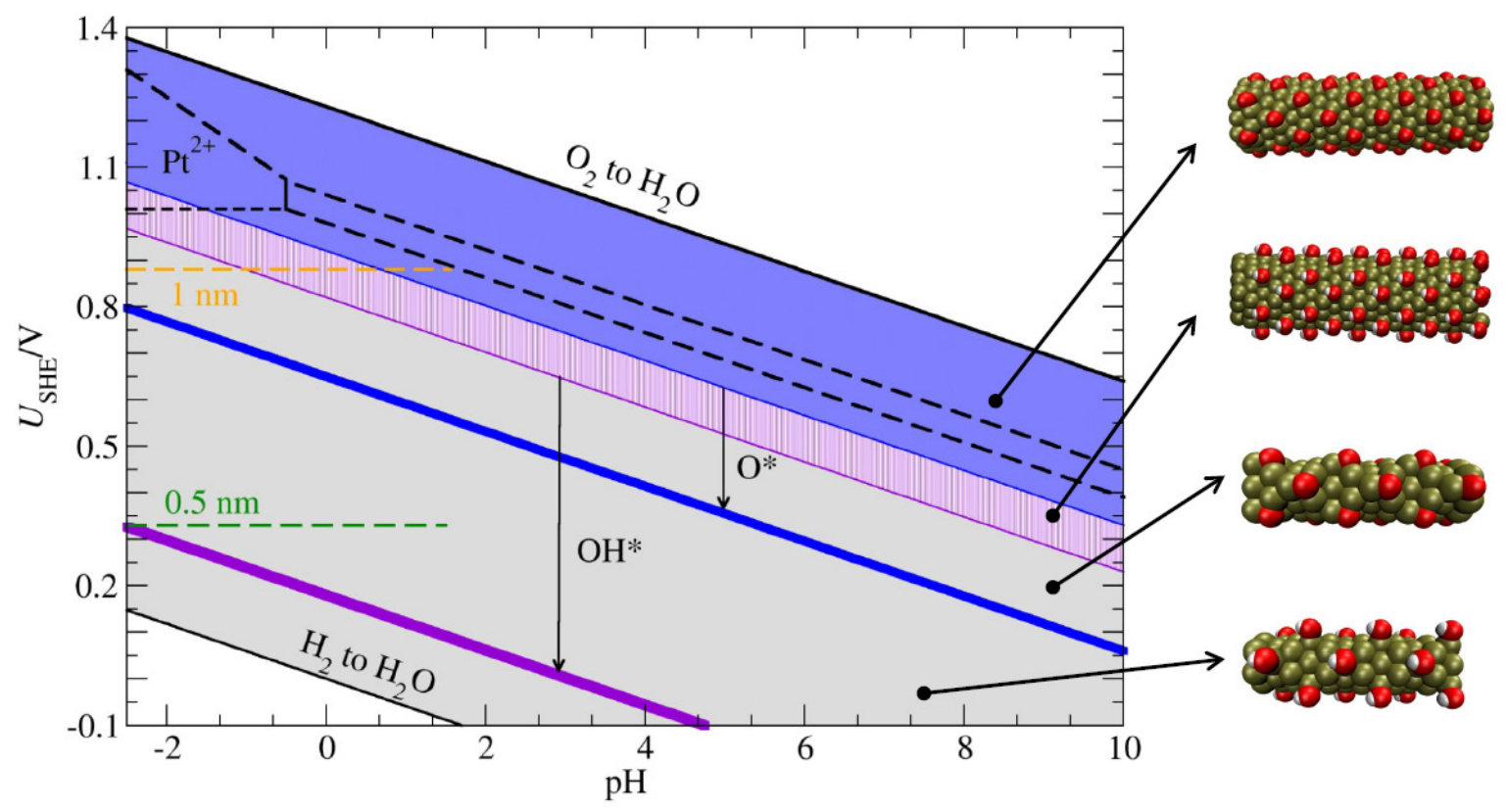

Figure: Calculated surface Pourbaix diagrams for Pt nanotubes compared to a bulk Pourbaix diagrams (black dashed lines) 


\section{Pt nanotubes - ab initio MD simulations in water}

Aim (1) characterize change of atomic and electronic structure on solvation

(2) structure of water around curved surfaces - water-surface interface models

$(6,6)$ and

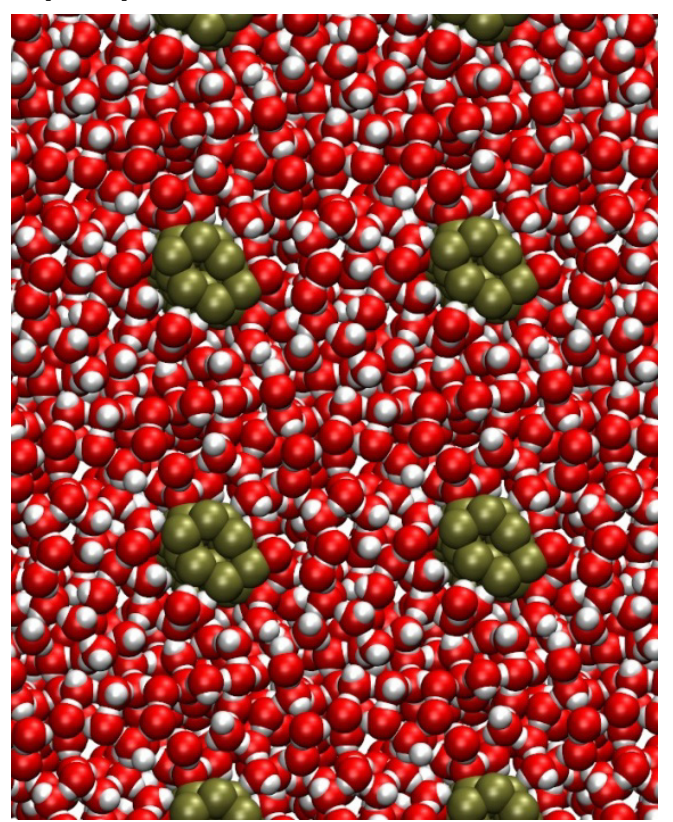

- Los Alamos
$(13,13)$ SWPtNT in water

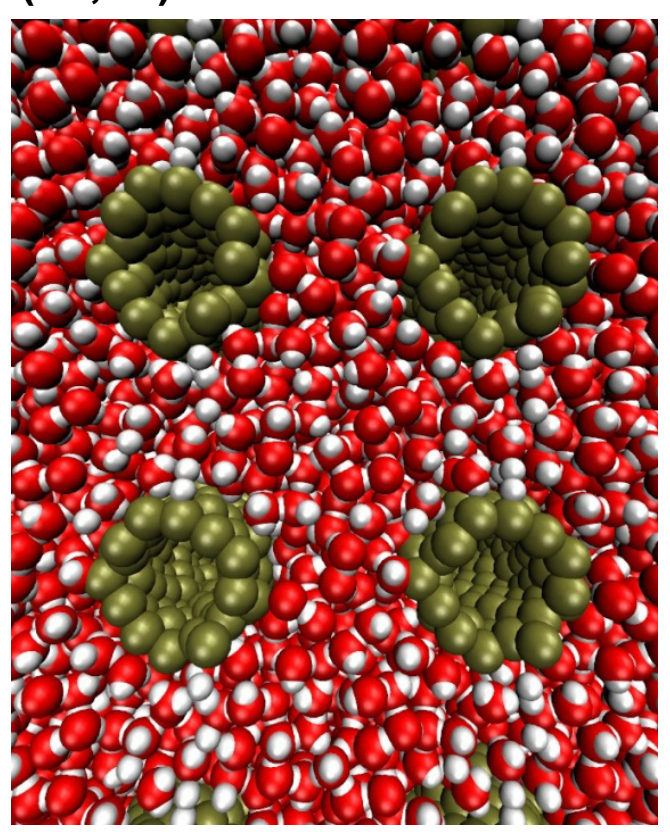

800 atom cell, 1300 MD steps in 24h, 480 processors, average $\sim 1 \mathrm{~min} / \mathrm{step}$ 


\section{Conclusions}

- smaller nanotubes ( $\sim 0.5 \mathrm{~nm})$ bind oxygen/hydroxyl more strongly than $\mathrm{Pt}(111)$ - poisoning

- larger single-wall nanotubes and nanowires $(\sim 1 \mathrm{~nm})$ bind oxygen/hydroxyl comparable or weaker than $\operatorname{Pt}(111) \Rightarrow$ reduced ORR overpotential

- control size/chirality - fine tuning of reactivity $\rightarrow$ separation of metal nanotubes by geometric specification or size

- hydroperoxyl dissociates on most of the adsorption sites $-4 \mathrm{e}^{-}$ORR without peroxide formation preferred mechanism

- all studied nanotubes more susceptible to electrochemical dissolution than $\mathrm{Pt}(111)$ potential corrosion problem 


\section{Acknowledgements}

\section{Thank you for you}

LANL LDRD program for postdoctoral fellowship

U.S. Department of Energy, Energy Efficiency and Renewable Energy for financial support

National Energy Research Scientific Computer Center, Pacific Northwest National Laboratory Advanced Computing Center
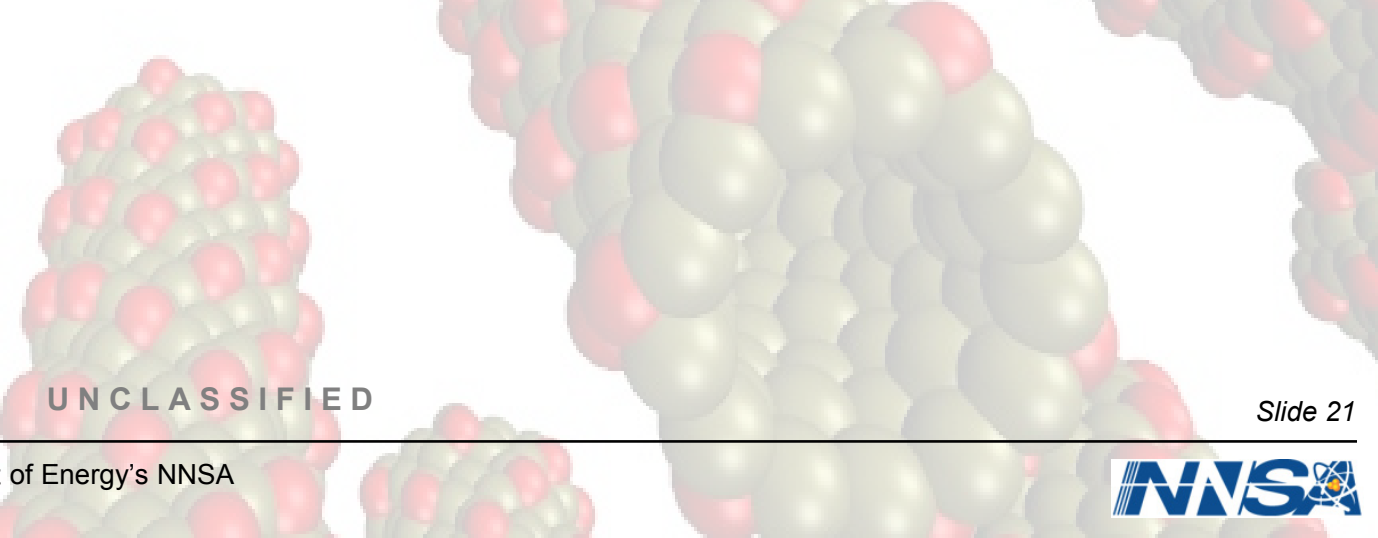